\title{
Association Between Silymarin Use and Age-related Macular Degeneration in Patients With Chronic Hepatic Diseases: a Population-based Retrospective Cohort Study
}

\author{
Mu-Ming Chien \\ Taipei Medical University \\ Hsiu-Chen Lin \\ Taipei Medical University \\ Li-Fen Lee \\ Taipei Medical University \\ Joseph Jordan Keller \\ Ohio State University \\ Li-Hsuan Wang ( $\square$ shiuan@tmu.edu.tw ) \\ Taipei Medical University
}

\section{Research Article}

Keywords: silymarin, age-related macular degeneration, chronic hepatic diseases, Silybum marianum, population-based retrospective cohort study

Posted Date: November 11th, 2021

DOl: https://doi.org/10.21203/rs.3.rs-993679/v1

License: (c) (i) This work is licensed under a Creative Commons Attribution 4.0 International License.

Read Full License 


\section{Abstract}

Silymarin is a bioflavonoid compound mostly used in patients with chronic hepatic diseases (CHDs). It has been shown to inhibit retinal angiogenesis in in vitro and in vivo animal studies. Age-related macular degeneration (AMD) is a leading cause of vision impairment worldwide, and no definite preventive measures for AMD exist at present. Through this study, we aimed to investigate whether the use of silymarin affects the risk of AMD in patients with CHDs. Cox proportional hazard models were used to assess the hazard ratio (HR) of AMD in this population-based retrospective cohort study. The CHDs was associated with a higher risk of AMD (adjusted hazard ratio (aHR): 1.33, 95\% $\mathrm{Cl} 1.22-1.46$ ), and the use of silymarin reduced the risk of AMD among patients with CHDs (aHR: $0.76,95 \% \mathrm{Cl}$ : 0.67-0.87). A higher accumulative dose (defined daily dose [DDD] $<631 \mathrm{mg}$ ) of silymarin was associated with a lower risk of AMD, but the difference was nonsignificant. In conclusion, CHDs were associated with a higher incidence of AMD, and the use of silymarin was associated with a reduced risk of AMD in patients with CHDs. However, a higher accumulative DDD of silymarin did not reduce the risk of AMD.

\section{Introduction}

Age-related macular degeneration (AMD) is a disease that affects the macular region of the retina, causing the progressive loss of central vision. It is currently the third leading cause of vision impairment worldwide, and the number of individuals with AMD is expected to reach approximately 200 million by 2020 , posing a global health burden ${ }^{1,2}$. AMD is a disease of the aging eye, with multiple factors including genetics and environmental factors affecting its course ${ }^{1,3}$. Among these factors, oxidative stress had attracted much interest. Large randomized controlled trials have shown beneficial effects of the use of high-dose oral antioxidant vitamins in slowing the progress of AMD, leading to their inclusion in the treatment of AMD by some authorities ${ }^{4-6}$. Other nutrients with antioxidant effects, such as anthocyanins and selenium, were also investigated ${ }^{7}$.

Silymarin, a bioflavonoid, is a natural compound extracted from Silybum marianum, or milk thistle ${ }^{8}$. Silymarin has been used as a traditional Chinese herbal medicine for more than 2,000 years, mostly in patients with chronic hepatic diseases (CHDs) such as viral hepatitis, nonalcoholic fatty liver disease, and cirrhosis $^{8}$. It was found to have multiple potential pharmacological properties, such as antioxidant, antiinflammatory, and hepatoprotective effects ${ }^{9}$. An in vitro study found that silibinin, the main bioactive component of silymarin, inhibited the secretion of vascular endothelial growth factor (VEGF) from retinal pigment epithelium cells ${ }^{10}$. In a rat model of AMD, it inhibited retinal edema and angiogenesis caused by VEGF and hypoxia conditions ${ }^{10}$. However, whether these results can be extrapolated to humans is still unknown. Thus, through this study, we aimed to investigate the effect of silymarin on the risk of AMD by using a nationwide health insurance database. Because silymarin is usually used in patients with CHDs, this specific population was analyzed.

\section{Materials And Methods}




\section{Data source}

This population-based, retrospective claim database study utilized the Longitudinal Health and Welfare Database (LHWD) provided by the Health and Welfare Data Science Center (HWDC) of Taiwan. This sampled database is derived from Taiwan's National Health Insurance database, which covers $99.9 \%$ of Taiwan's population as of $2014^{11}$. The HWDC established and verified the sampled database.

\section{Study design and patient selection criteria}

The study period was from 2001 to 2014, and our patient enrollment period was from 2001 to 2009 . The study flowchart is depicted in Figure 1. The International Classification of Diseases, ninth revision (ICD-9) code 571.X was used for the confirmation of CHD diagnoses, and codes 362.50, 362.51, and 362.52 were used for the diagnosis of AMD. Patients diagnosed as having CHDs twice from January 1, 2001 to December 31, 2009 were enrolled. Those aged $<40$ years were excluded. The diagnosis date was defined as the date of the first diagnosis of CHDs, and the index date was defined as the date of the first recorded use of silymarin for Study Group I.

Among the patients diagnosed as having CHDs, Study Group I included patients with silymarin use and excluded patients who had used silymarin before the diagnosis date, those who had used silymarin for fewer than 90 days within 1 year after index date, those who had AMD before the diagnosis date, and those who were diagnosed as having AMD within 1 year after the index date. Among patients diagnosed as having CHDs who did not use silymarin, those diagnosed as having AMD before the diagnosis date were excluded, and those remaining were grouped into Study Group II.

From patients without CHDs or silymarin use, we randomly selected a group of patients and assigned them to the Comparison Group, which was 1:1 matched with Study Group II by age, sex, and year of diagnosis date. Because the patients in the Comparison Group were not diagnosed as having CHDs, the date used for matching was called the reference date in the Comparison Group. Patients from the Comparison Group who were diagnosed as having AMD before the reference date were excluded.

This study was approved by Ethics Committee of Taipei Medical University (TMU-JIRB, No.: N201610012). Because all NHIRD data are delinked and deidentified, the requirement for obtaining informed consent was waived. We confirm that all methods were performed in accordance with the relevant guidelines and regulations and the study had been performed in accordance with the Declaration of Helsinki.

\section{Risk factors and confounding factors}

The potential risk factors for AMD, including hypertension, diabetes mellitus, hyperlipidemia, cerebrovascular diseases, coronary artery diseases, heart failure, peripheral vascular diseases, gastrointestinal disorders, dementia, obesity, tobacco use disorder, and alcohol abuse were identified in the patients. The potential confounding factors of medication use, including that of lipid-lowering agents 
(statin, fibrate), antihypertensive agents (angiotensin-converting-enzyme inhibitors, angiotensin II receptor blockers, calcium channel blockers), and aspirin, were also evaluated.

\section{Outcome measurement}

Because we aimed to investigate the long-term use of silymarin in patients with CHDs, only those who had used silymarin for more than 90 days per year were included. We evaluated the occurrence of AMD in each group as the primary outcome. For the evaluation of the dose-response as the secondary outcome, the Anatomical Therapeutic Chemical (ATC)/Defined Daily Dose (DDD) system was used ${ }^{12}$. Owing to lack of data regarding silymarin DDD in World Health Organization suggestions, we set its DDD to $420 \mathrm{mg}$ according to the package insert ${ }^{13}$.

\section{Statistical analysis}

Among the different patient groups, means with standard deviations were used to describe age, and proportions were used to describe all other variables (including sex, comorbidities, and co-medication). Student's $t$ test and Pearson's chi-squared test were performed to evaluate the differences in all the other baseline characteristics. The Cox proportional hazards regression model was used to analyze the risk of AMD between the groups. The potential risk factors mentioned in the previous section were included in the model.

Two-tailed hypothesis tests were used in all analyses, and $\mathrm{p}<0.05$ indicated statistical significance. SAS (version 9.4; SAS Institute, Cary, NC, USA) was used for all statistical analyses.

\section{Results}

\section{Baseline characteristics}

The LHWD database consisted of 113,387 patients aged $>40$ years and diagnosed as having CHDs at least twice from 2001 to 2009. Among them, 14,579 were enrolled into Study Group I (patients with CHDs who used silymarin) and 54,866 were enrolled into Study Group II (patients with CHDs who did not use silymarin). The Comparison Group (the 1:1 matched control group, patients without CHDs or silymarin use) consisted of 53,320 patients. The baseline patient characteristics are shown in Table 1. All characteristics other than obesity significantly differed between Study Groups I and II. Between Study Group II and the Comparison Group, all characteristics other than sex significantly differed. 
Table 1

Baseline characteristics of the study and comparison groups

\section{Patients with CHDs}

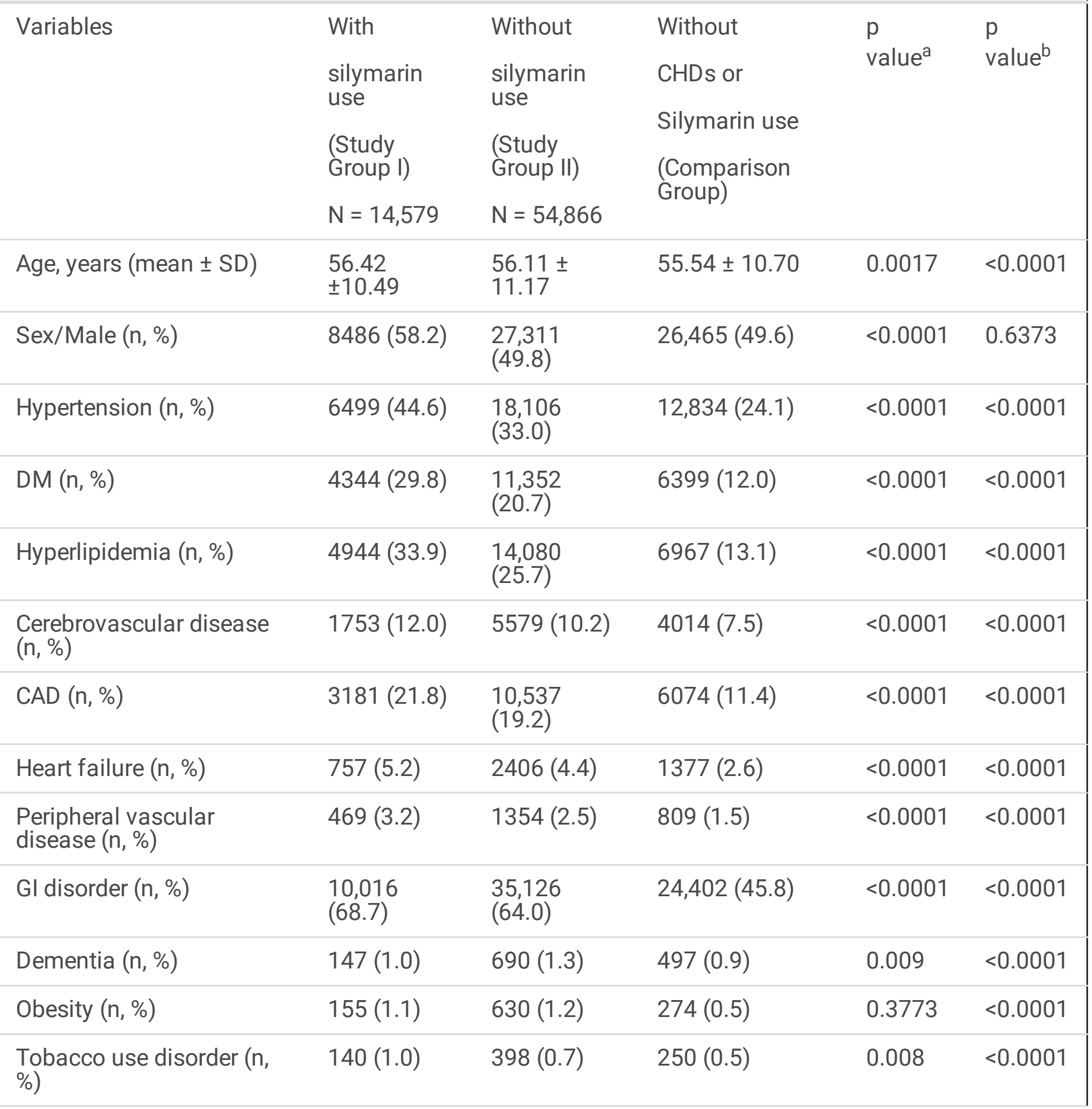

CHDs, chronic hepatic diseases; DM, diabetes mellitus; CAD, coronary artery disease; $\mathrm{GI}$, gastrointestinal; $C C B$, calcium channel blocker; $A C E I$, angiotensin-converting-enzyme inhibitor; $A R B$, angiotensin II receptor blocker; SD, standard deviation; GI, gastrointestinal

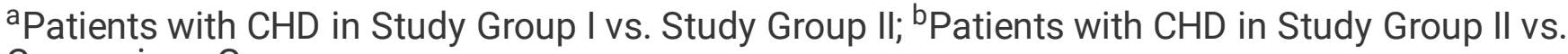

Comparison Group 


\begin{tabular}{|llllll|}
\hline \multicolumn{5}{|c|}{ Patients with CHDs } \\
\hline Alcohol abuse (n, \%) & $76(0.5)$ & $125(0.2)$ & $36(0.1)$ & $<0.0001$ & $<0.0001$ \\
\hline Statins (n, \%) & $2051(14.1)$ & $5909(10.8)$ & $3179(6.0)$ & $<0.0001$ & $<0.0001$ \\
\hline Fibrate (n, \%) & $1642(11.3)$ & $4018(7.3)$ & $2140(4.0)$ & $<0.0001$ & $<0.0001$ \\
\hline Aspirin (n, \%) & $456(3.1)$ & $1406(2.6)$ & $1228(2.3)$ & 0.0004 & 0.0056 \\
\hline CCB (n, \%) & $5939(40.7)$ & $\begin{array}{l}16,173 \\
(29.5)\end{array}$ & $11,473(21.5)$ & $<0.0001$ & $<0.0001$ \\
\hline ACEI (n, \%) & $3952(27.1)$ & $\begin{array}{l}10,132 \\
(18.5)\end{array}$ & $7347(13.8)$ & $<0.0001$ & $<0.0001$ \\
\hline ARB (n, \%) & $2174(14.9)$ & $5743(10.5)$ & $3630(6.8)$ & $<0.0001$ & $<0.0001$ \\
\hline $\begin{array}{l}\text { CHDs, chronic hepatic diseases; DM, diabetes mellitus; CAD, coronary artery disease; GI, } \\
\text { gastrointestinal; CCB, calcium channel blocker; ACEI, angiotensin-converting-enzyme inhibitor; ARB, } \\
\text { angiotensin II receptor blocker; SD, standard deviation; Gl, gastrointestinal }\end{array}$ & \\
\hline $\begin{array}{l}\text { apatients with CHD in Study Group I vs. Study Group II; bPatients with CHD in Study Group II vs. } \\
\text { Comparison Group }\end{array}$ & & \\
\hline
\end{tabular}

\section{Risk of AMD in patients with CHDs, with or without silymarin use}

The risk of AMD in the different groups is shown in Table 2. Among patients with CHDs (Study Groups I and II), use of silymarin reduced the risk of AMD; the adjusted hazard ratio (aHR) was 0.76 (95\% Cl: 0.670.87). Among patients without silymarin use (Study Group II and Comparison Group), the diagnosis of CHDs was associated with a significantly higher risk of AMD (aHR 1.33, 95\% $\mathrm{Cl} 1.22-1.46$ ). The results revealed that although patients with $\mathrm{CHD}$ were associated with a higher rate of $A M D$, silymarin use was associated with a reduction in the occurrence of AMD. 
Table 2

Crude hazard ratios (HRs) and adjusted HRs for the risk of age-related macular degeneration (AMD) between the study and comparison groups

\begin{tabular}{|c|c|c|c|}
\hline \multicolumn{4}{|c|}{ Patients with CHDs } \\
\hline \multirow[t]{3}{*}{ Results } & $\begin{array}{l}\text { With Silymarin } \\
\text { use }\end{array}$ & $\begin{array}{l}\text { Without Silymarin } \\
\text { use }\end{array}$ & $\begin{array}{l}\text { Without CHDs or Silymarin } \\
\text { use }\end{array}$ \\
\hline & (Study Group I) & (Study Group II) & (Comparison Group) \\
\hline & $N=14,579$ & $N=54,866$ & $N=53,320$ \\
\hline AMD (n, \%) & $292(2.00)$ & $1,394(2.54)$ & $864(1.62)$ \\
\hline Crude HR (95\% Cl) & $\begin{array}{l}0.79(0.69- \\
0.89)^{\star \star \star}\end{array}$ & 1 & - \\
\hline $\begin{array}{l}\text { Adjusted HR }(95 \% \\
\text { Cl) }\end{array}$ & $\begin{array}{l}0.76(0.67- \\
0.87)^{\star \star \star}\end{array}$ & 1 & - \\
\hline Crude HR (95\% Cl) & & 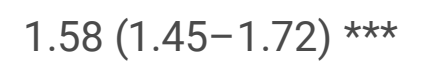 & 1 \\
\hline $\begin{array}{l}\text { Adjusted HR (95\% } \\
\text { Cl) }\end{array}$ & & $1.33(1.22-1.46) * \star \star$ & 1 \\
\hline \multicolumn{4}{|c|}{$\begin{array}{l}\text { CHDs, chronic hepatic diseases; } \mathrm{AMD} \text {, age-related macular degeneration; } \mathrm{HR} \text {, hazard ratio; } \mathrm{Cl} \text {, } \\
\text { confidence interval; SD, standard deviation }\end{array}$} \\
\hline \multicolumn{4}{|c|}{$\begin{array}{l}\text { Adjusted for age, sex, hypertension, diabetes, hyperlipidemia, cerebrovascular disease, coronary artery } \\
\text { disease, heart failure, peripheral vascular disease, gastrointestinal disorder, dementia, obesity, tobacco } \\
\text { use disorder, alcohol abuse, statin, fibrate, aspirin, calcium channel blocker, angiotensin-converting- } \\
\text { enzyme inhibitor, and angiotensin II receptor blocker }\end{array}$} \\
\hline$\star \star * x p<0.001, * * p<$ & $p<0.05$ & & \\
\hline
\end{tabular}

\section{Relation between risk of AMD and silymarin dose}

Patients in Study Group I were further categorized into five subgroups according to the total exposure dose accumulation of silymarin (Table 3). Compared with Study Group II, the risk of AMD decreased as the total exposure dose accumulation of silymarin increased; however, the difference was not statistically significant ( $p$ for trend $>0.05$ ). The aHRs in the $<90,>90-270,>270-450$," and $>450-630 \mathrm{mg}$ DDD groups were 0.78 (95\% Cl: $0.62-0.97), 0.78$ (95\% Cl: 0.64-0.94), 0.69 (95\% Cl: $0.50-0.96)$, and 0.59 (95\% Cl: $0.35-0.98)$, respectively. However, the risk of AMD in patients with total silymarin exposure of more than $630 \mathrm{mg}$ DDD was not significantly different from that in patients in Study Group II (aHR 0.86, 95\% Cl: $0.63-1.16)$. 
Table 3

Dose-effect analysis of the risk of age-related macular degeneration in patients with chronic hepatic diseases who used silymarin

\begin{tabular}{|c|c|c|c|c|c|c|}
\hline \multirow[t]{3}{*}{ Results } & \multirow{3}{*}{$\begin{array}{l}\text { Patients with CHDs and } \\
\text { without silymarin use } \\
\text { (Study Group II) } \\
\mathrm{N}=54,866\end{array}$} & \multicolumn{5}{|c|}{ Patients with CHDs and silymarin use (Study Group I) } \\
\hline & & \multirow{2}{*}{$\begin{array}{l}<90 \\
\mathrm{mg} \\
\mathrm{DDD} \\
\mathrm{N}= \\
3,620\end{array}$} & \multirow{2}{*}{$\begin{array}{l}90-270 \\
\mathrm{mg} \text { DDD } \\
\mathrm{N}= \\
5,714\end{array}$} & \multirow{2}{*}{$\begin{array}{l}271-450 \\
\mathrm{mg} \mathrm{DDD} \\
\mathrm{N}=2,088\end{array}$} & \multirow{2}{*}{$\begin{array}{l}451-630 \\
\mathrm{mg} \mathrm{DDD} \\
\mathrm{N}=1,088\end{array}$} & \multirow{2}{*}{$\begin{array}{l}>631 \\
\mathrm{mg} \\
\mathrm{DDD} \\
\mathrm{N}= \\
2,069\end{array}$} \\
\hline & & & & & & \\
\hline $\begin{array}{l}\mathrm{AMD}(\mathrm{n}, \\
\%)\end{array}$ & $1,394(2.54)$ & $\begin{array}{l}79 \\
(2.18)\end{array}$ & $\begin{array}{l}118 \\
(2.07)\end{array}$ & $37(1.77)$ & $15(1.38)$ & $\begin{array}{l}43 \\
(2.08)\end{array}$ \\
\hline $\begin{array}{l}\text { Crude } \\
\text { HR }\end{array}$ & 1 & 0.86 & 0.81 & 0.70 & 0.54 & 0.82 \\
\hline$(95 \% \mathrm{Cl})$ & & $\begin{array}{l}(0.68- \\
1.07)\end{array}$ & $\begin{array}{l}(0.67- \\
0.98)^{\star}\end{array}$ & $\begin{array}{l}(0.50- \\
0.96)^{\star}\end{array}$ & $\begin{array}{l}(0.32- \\
0.90)^{\star}\end{array}$ & $\begin{array}{l}(0.60- \\
1.10)\end{array}$ \\
\hline $\begin{array}{l}\text { Adjusted } \\
\text { HR }\end{array}$ & 1 & 0.78 & 0.78 & 0.69 & 0.59 & 0.86 \\
\hline$(95 \% \mathrm{Cl})$ & & $\begin{array}{l}(0.62- \\
0.97)^{\star}\end{array}$ & $\begin{array}{l}(0.64- \\
0.94)^{\star \star}\end{array}$ & $\begin{array}{l}(0.50- \\
0.96)^{\star}\end{array}$ & $\begin{array}{l}(0.35- \\
0.98)^{\star}\end{array}$ & $\begin{array}{l}(0.63- \\
1.16)\end{array}$ \\
\hline \multicolumn{7}{|c|}{$\begin{array}{l}\text { CHDs, chronic hepatic diseases; AMD, age-related macular degeneration; } \mathrm{HR} \text {, hazard ratio; } \mathrm{Cl} \text {, } \\
\text { confidence interval; SD, standard deviation; DDD, defined daily dose }\end{array}$} \\
\hline \multicolumn{7}{|c|}{$\begin{array}{l}\text { Adjusted for age, sex, hypertension, diabetes, hyperlipidemia, cerebrovascular disease, coronary artery } \\
\text { disease, heart failure, peripheral vascular disease, gastrointestinal disorder, dementia, obesity, tobacco } \\
\text { use disorder, alcohol abuse, statin, fibrate, aspirin, calcium channel blocker, angiotensin-converting- } \\
\text { enzyme inhibitor, and angiotensin II receptor blocker }\end{array}$} \\
\hline$\star * p<0.01$ & $p<0.05$ & & & & & \\
\hline
\end{tabular}

\section{Discussion}

In this study, we compared the incidence of AMD among three groups of patients by using a nationwide database: those with CHDs who used silymarin (Study Group I), those with CHDs who did not used silymarin (Study Group II), and those without CHDs or silymarin use (Comparison Group).

The study had stringent criteria; the included patients were required to have been diagnosed as having CHDs on at least two different occasions. To better evaluate the effect of silymarin on the occurrence of AMD, we included only patients with long-term silymarin use after the diagnosis of CHDs. Those who had AMD before using silymarin or within 1 year after initiating silymarin were excluded.

We found that patients with CHDs who did not use silymarin had a higher risk of AMD, with an aHR of $1.33(95 \% \mathrm{Cl}, 1.22-1.46)$. Among patients with $\mathrm{CHDs}$, use of silymarin was associated with a lower risk of AMD (aHR 0.76, 95\% Cl 0.67-0.87); however, no significant dose-dependent response was observed. 
AMD is classified into two forms, a nonneovascular or "dry" form and a neovascular "wet" form. AntiVEGF agents have shown to be an effective treatment for neovascular AMD, but no effective preventive measures exist ${ }^{14}$. Antioxidant vitamin supplements may slow the progression of AMD; however, a metaanalysis suggested that they do not prevent or delay the onset of AMD [ $\left.{ }^{15,16}\right]$. Various other nutrients have been tested for their possible preventive effects against AMD, and the findings of the current study add silymarin to the list ${ }^{7}$.

Pretreatment of retinal pigmented epithelial cells with silibinin, the main component of silymarin, was shown to inhibit the hypoxia-induced pathway in a previous study, reducing VEGF secretion, thereby preventing hypoxia-induced angiogenesis in a rat model of $A M D^{10}$. Other than $A M D$, in vitro studies have shown that silibinin can protect retinal ganglion cells from blue light-induced injury ${ }^{17}$ and prevent hyperpermeability induced by diabetic conditions in human retinal endothelial cells ${ }^{18}$. Further human studies are warranted to confirm the efficacy of silibinin in preventing these eye conditions.

The risk factors of AMD include age, genetics, smoking status, and diet ${ }^{1}$. Liver disease was previously not considered a risk factor for AMD, but some case series have reported that retinopathy occurs in approximately $15 \%$ of patients with liver cirrhosis and $32 \%$ of patients with chronic hepatitis $C^{19,20}$. The authors of the aforementioned studies have suggested that loss of synthetic function of the liver and hemodynamic effects of portal hypertension in patients with cirrhosis might contribute to retinopathy, and immune-mediated ischemic retinopathy might be the pathogenesis underlying chronic $\mathrm{C}$ hepatitis associated retinopathy ${ }^{19,21}$. Pathologic angiogenesis is closely related to the fibrogenic progression of CHDs, with hypoxia and hypoxia-inducible factors playing a major role, and in vitro study has shown that antiangiogenic therapy is highly effective in significantly reducing fibrogenic progression ${ }^{22}$. We suggested that this pathologic angiogenesis also occurs in the retina, leading to a higher incidence of $\mathrm{AMD}$ in patients with $\mathrm{CHDs}$, and can be suppressed with silymarin use.

The current study had some limitations. Because this was a retrospective study based on information from the health insurance database, the type of AMD that occurred, the type of CHD that was more related to the higher risk of AMD, and the type of AMD whose incidence was reduced by silymarin were difficult to discriminate. Further prospective trials with silymarin are warranted to answer these questions and help elucidate its mechanism.

In conclusion, $\mathrm{CHDs}$ were associated with a higher incidence of AMD, and the use of silymarin was associated with a reduced risk of AMD in patients with CHDs. However, a higher dose of silymarin was not associated with a significantly lower risk of AMD.

\section{Declarations}

\section{Author contributions:}


Mu-Ming Chien and Hsiu-Chen Lin contributed to conception and design, analysis and interpretation of data, drafting the article and revising it critically for important intellectual content, and final approval of the version to be published. Li-Fen Lee contributed to conception and design, analysis and interpretation of data, and final approval of the version to be published. Joseph Jordan Keller partly contributed to acquisition of data, analysis and interpretation of data, revising it critically for important intellectual content and final approval of the version to be published. Li-Hsuan Wang contributed to conception and design, analysis and interpretation of data, drafting the article, revising it critically for important intellectual content and final approval of the version to be published.

\section{Acknowledgments:}

This manuscript was edited by Wallace Academic Editing.

\section{Conflict of interest:}

All authors have no conflict of interest, financial or otherwise.

\section{Funding:}

no funding.

\section{References}

1. Mitchell P, Liew G, Gopinath B \& Wong TY. Age-related macular degeneration. Lancet 2018;392:114759.

2. Bourne RR, et al. Causes of vision loss worldwide, 1990-2010: a systematic analysis. Lancet Glob Health 2013;1:e339-49.

3. Veritti $D$, et al. State-of-the art pharmacotherapy for non-neovascular age-related macular degeneration. Expert Opin Pharmacother 2020;21:773-84.

4. Age-Related Eye Disease Study Research G. A randomized, placebo-controlled, clinical trial of highdose supplementation with vitamins $\mathrm{C}$ and $\mathrm{E}$ and beta carotene for age-related cataract and vision loss: AREDS report no. 9. Arch Ophthalmol 2001;119:1439-52.

5. Age-Related Eye Disease Study 2 Research G. Lutein + zeaxanthin and omega-3 fatty acids for agerelated macular degeneration: the Age-Related Eye Disease Study 2 (AREDS2) randomized clinical trial. JAMA 2013;309:2005-15.

6. Flaxel CJ, et al. Age-Related Macular Degeneration Preferred Practice Pattern(R). Ophthalmology 2020;127:P1-P65.

7. Khoo HE, Ng HS, Yap WS, Goh HJH \& Yim HS. Nutrients for Prevention of Macular Degeneration and Eye-Related Diseases. Antioxidants (Basel) 2019;8.

8. Federico A, Dallio M \& Loguercio C. Silymarin/Silybin and Chronic Liver Disease: A Marriage of Many Years. Molecules 2017;22. 
9. Abenavoli L, Izzo AA, Milic N, Cicala C, Santini A \& Capasso R. Milk thistle (Silybum marianum): A concise overview on its chemistry, pharmacological, and nutraceutical uses in liver diseases. Phytother Res 2018;32:2202-13.

10. Lin $\mathrm{CH}$, et al. Silibinin inhibits VEGF secretion and age-related macular degeneration in a hypoxiadependent manner through the PI-3 kinase/Akt/mTOR pathway. Br J Pharmacol 2013;168:920-31

11. Handa JT, et al. A systems biology approach towards understanding and treating non-neovascular age-related macular degeneration. Nat Commun 2019;10:3347.

12. Evans JR \& Lawrenson JG. Antioxidant vitamin and mineral supplements for preventing age-related macular degeneration. Cochrane Database Syst Rev 2012:CD000253.

13. Evans JR \& Lawrenson JG. Antioxidant vitamin and mineral supplements for slowing the progression of age-related macular degeneration. Cochrane Database Syst Rev 2012;11:CD000254.

14. Shen $Y$, et al. Silibinin declines blue light-induced apoptosis and inflammation through MEK/ERK/CREB of retinal ganglion cells. Artif Cells Nanomed Biotechnol 2019;47:4059-65.

15. Garcia-Ramirez M, Turch M, Simo-Servat O, Hernandez C \& Simo R. Silymarin prevents diabetesinduced hyperpermeability in human retinal endothelial cells. Endocrinol Diabetes Nutr 2018;65:2005.

16. Onder C, et al. Relationship between retinopathy and cirrhosis. World J Gastroenterol 2005;11:2193-6.

17. Abe T, et al. Clinical characteristics of hepatitis $C$ virus-associated retinopathy. Jpn J Ophthalmol 1995;39:411-9.

18. Zegans ME, Anninger W, Chapman C \& Gordon SR. Ocular manifestations of hepatitis C virus infection. Curr Opin Ophthalmol 2002;13:423-7.

19. Bocca C, Novo E, Miglietta A \& Parola M. Angiogenesis and Fibrogenesis in Chronic Liver Diseases. Cell Mol Gastroenterol Hepatol 2015;1:477-88.

20. National Health Insurance Administration MoHaW, Taiwan, R.O.C. National Health Insurance Annual Report 2014-2015. 2014.

21. Purpose of the ATC/DDD system. 2018. (Accessed 2021-01-23)

22. Medication Identification Query. n.d. (Accessed 2021-01-23, at https://info.fda.gov.tw/MLMS/H0004.aspx.)

\section{Figures}



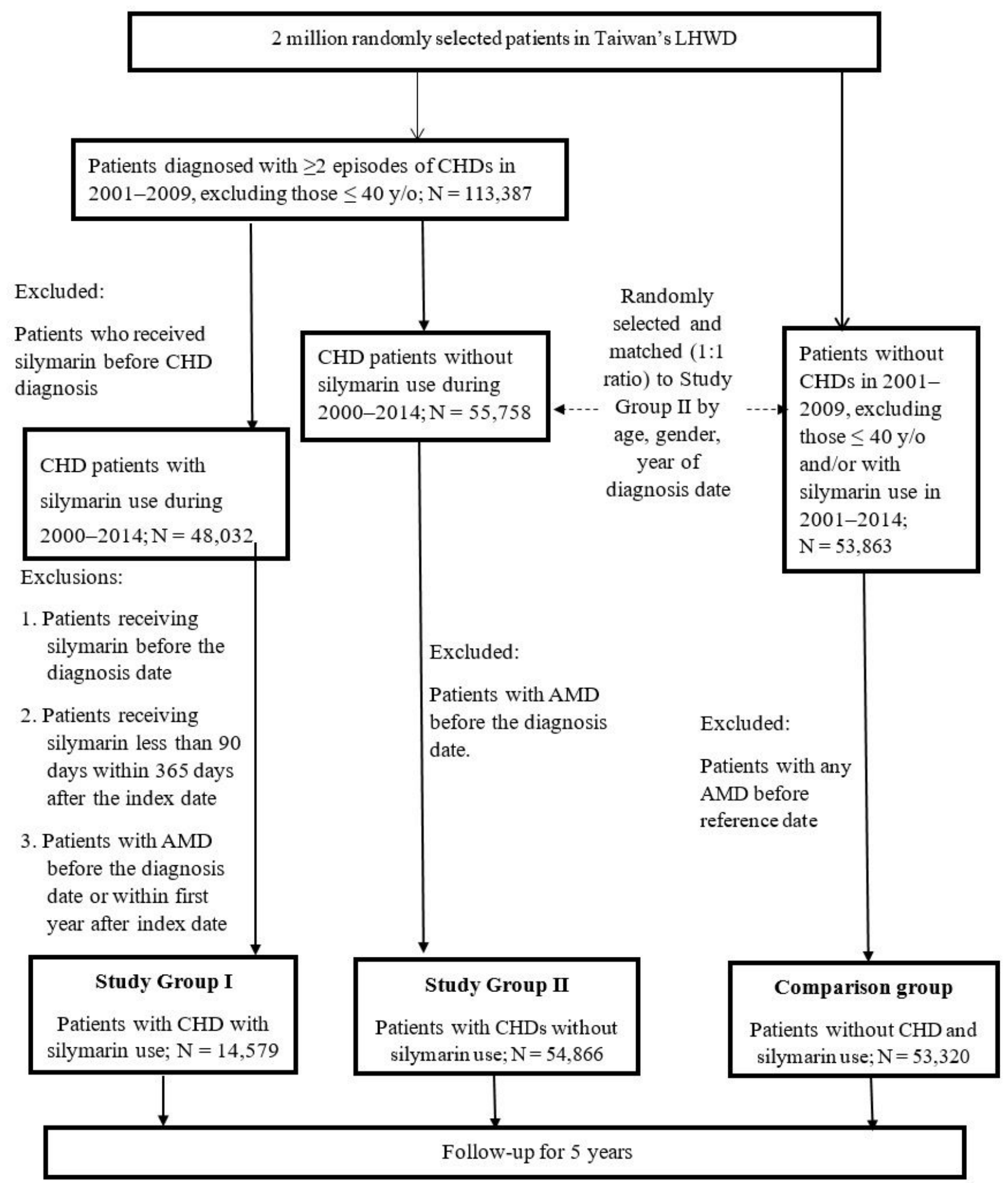

\section{Figure 1}

Study flowchart LHWD: Longitudinal Health and Welfare Database. Diagnosis Date: the first date of CHDs diagnosis. Index Date: The first date of recorded silymarin use. Reference date of the patient in Comparison Group is the diagnosis date of the matched patient in Study Group II. 